\title{
As (contra) reformas educacionais e o depauperamento da experiência (Erfahrung) na escola
}

\author{
The educational (counter) reforms and the impoverishment of \\ experience (Erfahrung) at school
}

\section{Ademir Henrique Manfré}

\section{Resumo}

O presente ensaio discorre sobre os estudos realizados no primeiro semestre de 2017 junto à disciplina de "Currículo e Escola" por mim ministrada em um curso de formação de professores. Essa investigação teve como objetivo discutir a temática das (contra) reformas educacionais e o processo de depauperamento da experiência (Erfahrung) na educaçấo escolar. O delineamento metodológico dessa análise se sustentou na reflexão e problematização de textos indicados pela disciplina, os quais serviram de sustentação teórico-metodológica para o debate proposto. Conceitos-chave da Teoria Crítica da Escola de Frankfurt - sociedade administrada, Indústria Cultural, semiformaçáo, emancipaçáo - apoiaram a nossa investigaçáo no sentido de evidenciar o modo como a escola da contemporaneidade necessita pensar uma formação que impeça o conformismo exacerbado. Desse modo, esse ensaio traz uma reflexáo sobre o papel da escola, analisando as propostas de (contra) reformas educacionais na atualidade.

\section{Palavras-chave}

Educação; Depauperamento; Neoliberalismo; (Contra) Reformas.

\begin{abstract}
This essay is about some analysis that I have developed during the first semester of 2017 in the discipline "Curriculum and School" taught by me in a teacher training course. In such investigation I aimed at discussing the topic of Educational (counter) reforms and the impoverishment process of experience (erfahrung) in school. The methodology of my analysis was grounded on the reflection and problem-making of texts indicated in the course, which was the theoretical-methodological support of the debate. Keyword of Critical Theory of Frankfurt School - as managed society, Cultural Industry, semi formation, and emancipation - were part of the investigation in order to highlight the way in which contemporary school needs to think about the student formation to prevents the exacerbated conformism. Thus, this essay brings a reflection about the role of school, analyzing the proposals of educational (counter) reforms in nowadays.
\end{abstract}

\section{Keywords}

Education; Impoverishment; Neoliberalism; (Counter) Reforms. 


\section{Introdução}

O presente ensaio discorre sobre os estudos realizados no primeiro semestre de 2017 junto à disciplina de "Currículo e Escola" por mim ministrada em um curso de formação de professores. Essa investigação teve como objetivo geral discutir a temática das (contra) reformas educacionais e o processo de depauperamento da experiência (Erfahrung) na educação escolar. O delineamento metodológico dessa análise se sustentou na reflexão e problematização de textos indicados pela disciplina, os quais serviram de sustentação teórico-metodológica para o debate proposto.

Conceitos-chave da Teoria Crítica da Escola de Frankfurt - sociedade administrada, Indústria Cultural, semiformação (Halbbildung), formação (Bildung) ${ }^{1}$ e emancipação - apoiaram a nossa investigação no sentido de evidenciar o modo como a escola da contemporaneidade necessita pensar uma formação que impeça o conformismo exacerbado. Desse modo, esse ensaio traz uma reflexão sobre o papel da escola, analisando as propostas de (contra) reformas educacionais na atualidade, evidenciando os seus limites para a (semi) formação do indivíduo. É possível anotar que, em pleno século XXI, a formação de professores pode contribuir com uma educação para a resistência e para o inconformismo.

Desse modo, nossa leitura é guiada pelo seguinte movimento de análise: focalizamos, num primeiro momento desse ensaio, alguns temas inseridos no debate atual sobre políticas neoliberais para a Educação. Em um segundo momento, a partir da leitura de textos dos filósofos de tradição frankfurtiana, teceremos algumas reflexóes sobre o processo do empobrecimento do pensar na escola.

Visando refletir sobre esses posicionamentos, o presente ensaio está embasado nas contribuiçôes teóricas que advém da Teoria Crítica, fundamentando as reflexões aqui realizadas. Desse ponto de vista, são colocadas em discussão as estratégias definidas pelo projeto neoliberal para a Educação, fomentadas na perda da dimensão crítica e emancipadora que, nas palavras de Adorno (1996), converteu a Bildung (formação cultural) em Halbbildung (semiformação).

\footnotetext{
${ }^{1}$ A Bildung representa, em Adorno (1996), o processo de estranhamento e reapropriação entre mundo e espírito, numa tensão contínua entre autonomia e adaptação, aceitação do mundo objetivo e negação, afirmação do espírito contrapondo à natureza. É um exercício em relação ao tempo, à memória e à história. Esse tensionamento constitui a cultura. A formação cultural (Bildung) submetida às relaçôes sociais regidas pela lógica mercantilista e instrumental acaba por se converter no que Adorno chamou de semiformação (Halbbildung). Para o frankfurtiano, "a semiformação é uma fraqueza em relação ao tempo, à memória, única mediação que realiza na consciência aquela síntese da experiência que caracterizou a formação cultural em outros tempos” (ADORNO, 1996, p. 406).
} 


\section{Educação e politicas neoliberais: a que pé anda a escola?}

Tratar da temática trabalho docente no contexto contemporâneo implica estudar as (contra) reformas educacionais promovidas no cenário brasileiro, levando em consideração os aspectos políticos, sociais, econômicos e culturais presentes na cena contemporânea. Diante do exposto, a escola tem sido chamada para cumprir a função de transformar a realidade do país.

Com a proposta de uma "educação para todos", coloca-se a educaçáo escolar como estratégia fundamental para a conquista de objetivos almejados em busca do desenvolvimento econômico. Assim, as políticas públicas brasileiras se concatenam com as diretrizes internacionais no sentido de oferecer uma melhoria da educação atrelada aos interesses dos organismos financeiros internacionais, como o Banco Mundial e o Fundo Monetário Internacional (FMI).

Amparadas pelas determinações desses organismos, as políticas educacionais atuais almejam ampliar o número de alunos nas escolas brasileiras, objetivando reduzir as estatísticas de reprovação e evasão escolar que todos os anos povoam a imprensa.

Sob essa perspectiva, de modo mais sistemático a partir de 1995, vêm sendo postas em prática reformas educacionais que alteram substancialmente as funçóes econômicas e político-sociais da escola brasileira. Essas reformas têm por finalidade formar, no espaço nacional intelectuais urbanos de novo tipo, ou seja, especialistas e dirigentes que, do ponto de vista técnico, possam aumentar a competitividade e produtividade do capital, nos marcos de um capitalismo periférico e, do ponto de vista ético-político, possam criar e difundir uma nova cidadania política [...] (NEVES, 2005, p. 104).

Conforme apontamos anteriormente, as reformas educacionais atuais postulam a necessidade de adequação do trabalho pedagógico às novas exigências oriundas do mundo do trabalho e da sociedade da informação. Como isso é possível? O Estado Neoliberal tem intervindo na Educação com uma política de adequação da profissão docente de acordo com os objetivos estabelecidos pelos interesses mercantilistas. Assim, o trabalho docente tende a sofrer consequências em função da sua especificidade, das metas e finalidades das (contra) reformas implantadas ou em processo de implantaçáo.

Considerando esse panorama, as políticas de formação de professores perfazem todo esse contexto de reformulaçôes, uma vez que lançam aos docentes 
novos desafios. Desvelar esse "novo" enfoque se torna fundamental no sentido de discutir os interesses que sustentam as políticas de formação de professores, em favor de uma análise crítica sobre o assujeitamento da educação à lógica mercadológica.

\section{Neoliberalismo e as (contra) reformas educacionais: (semi) formar? (Con) formar?}

Pensar a temática da formação cultural na educação brasileira implica muitos desafios. Oliveira (2003) afirma que, no que se refere à formação para as competências e habilidades requeridas pela sociedade tecnológica, tornou-se necessário um novo tipo de Estado, mais enxuto, ancorado nas mudanças tecnológicas e organizacionais das economias mundiais.

Surgiu então a inevitável necessidade de se configurar o Estado neoliberal ${ }^{2}$, que pressupóe mudanças fundamentais na sua gerência com relação aos serviços essenciais, como por exemplo, a Educaçáo. Pimenta e Anastasiou (2002) anotam que a noção de competência nas reformas educacionais brasileiras teve início com a Lei de Diretrizes e Bases da Educação Nacional - Lei n. 9394/96 (BRASIL, 1996), que trata da Educação Básica e Profissional.

Delineia-se aqui uma ideia que permeará o nosso debate: as propostas formativas da atualidade são fundamentadas, essencialmente, em projetos políticos neoliberais entendidos como estratégicos para o sucesso do modelo mercadológico ${ }^{3}$. Como consequência, as políticas educacionais atuais enfatizam uma formação com caráter pragmático, que tem na competência profissional o foco central.

${ }^{2} \mathrm{O}$ projeto neoliberal é ancorado na organização de um Estado mínimo, mediante privatização, desregulamentação, flexibilização (elemento este presente nas reformas educacionais as quais tratamos aqui), terceirização e globalização da economia. Seriam de (des) responsabilização do Estado a saúde, a educação, a justiça, a segurança, a habitação, as políticas assistenciais, por exemplo.

${ }^{3}$ Retomando o contexto da sociedade tecnológica e o novo ambiente produtivo, vê-se que é exigida uma formação que inclui flexibilidade, capacidade de executar diferentes tarefas, capacidade de solucionar problemas. O perfil e a formação cultural dos indivíduos estão sendo fundamentalmente valorizados nos processos de recrutamento para o mercado de trabalho. Sobressaem, dessas considerações, dois apontamentos: 1) Pode a educação subordinar-se às necessidades do mercado de trabalho? 2) Subordinar-se a tais exigências implica aceitar a competição capitalista e destituir-se da capacidade crítica e contestatória? 
Ao pensar a Educação de uma forma mercadológica, a sociedade tem valorizado os conhecimentos que servem ao mercado, por isso há a valorização de algumas disciplinas (como Português e Matemática) e a consequente desvalorização das demais [...]. O Estado tem continuado a reforçar o seu poder coercitivo e a incentivar a lógica do mercado por meio da implantação de diversos sistemas de avaliação [...]. O Estado continuou a exercer o seu controle através do currículo e na definição das competências (SANTANA, 2017, p. 88-89).

No que se refere à formação docente, de acordo com Santana (2017), as políticas de formação de professores sustentam a tese de uma nova concepção de professor, assemelhando-o a um tecnólogo do ensino. Essa discussão anuncia uma problemática implicada no campo da Pedagogia: essas políticas definem os conhecimentos básicos considerados imprescindíveis para a formação de professores da Educação Básica, limitando-se ao aspecto das competências e habilidades tão almejadas.

É do conhecimento de todos os envolvidos em Educação escolar que um dos pilares $^{4}$ da Educação é o "aprender a aprender" constantemente, muitas vezes desvinculado do aprender a pensar. Continuamos nossa exposição mantendo o nosso objetivo inicial que é o de discutir as (contra) reformas educacionais e os processos (semi) formativos requeridos pela sociedade do conhecimento.

Ao pensarmos as características da realidade educacional sob o enfoque da doutrina neoliberal, notamos que elas não se distanciam dos objetivos requeridos por uma empresa: competitividade, lucratividade, produtividade, inovação, espírito empreendedor, aprender a aprender, redução de custos, que vença o melhor, o mais esforçado, o mais destacado. Santana (2017, p. 86) considera que "o objetivo dos sistemas de ensino passa a ser atingir metas, o que não significa, necessariamente, um aprendizado, uma vez que é possível (e mais barato) treinar estudantes para fazer provas do que desenvolver um ensino que o leve ao pensamento crítico".

Duas breves observações se destacam nesse ponto de nossa exposição. A primeira é que as mudanças socioeconômicas exigidas pelo alinhamento do Estado à

\footnotetext{
${ }^{4}$ Em "Educação: um tesouro a descobrir", coordenado por Jacques Delors (2012), se evidencia as quatro aprendizagens de uma Educação para o século XXI: 1) aprender a conhecer; 2) aprender a fazer; 3) aprender a conviver e 4) aprender a ser. Esses quatro elementos não podem ser vivenciados de forma fragmentada, traduzindo-se como quatro vias de uma formação continuada no processo de aquisição do conhecimento.
} 
doutrina neoliberal ${ }^{5}$ trouxeram novas exigências para as políticas de formação de professores. A segunda é que a racionalidade instrumental presente nas (contra) reformas educacionais desconsideram uma reflexão crítica e emancipadora.

Diante da amplitude que caracteriza a temática, as reflexões desenvolvidas até o presente momento nos permitem afirmar que, nas últimas décadas, um conjunto de reformas foram levadas a cabo pelo viés do Neoliberalismo, gerando uma série de mudanças na funçáo social da escola. A questáo que nos interessa é repensar sobre as políticas de formaçáo docente na atualidade na busca de alternativas para a resistência à lógica neoliberal.

Todo o empenho do governo federal em estruturar a Educação brasileira consoante com os ditames do Banco Mundial e do FMI gerou uma variedade de dispositivos legais que regulamentam essas mudanças. A literatura atual sobre as (contra) reformas educacionais tem mostrado que o contexto da sociedade tecnológica e o ambiente produtivo exigem uma formação que inclui flexibilidade 6 , capacidade de exercer múltiplos papéis, capacidade de solucionar problemas, dentre outros.

No contexto das novas configurações, entre as várias reformas propostas para a Educação hoje, chama-nos a atenção a nova reforma do Ensino Médio ${ }^{7}$, implementada pela medida provisória n. 746, de 22 de setembro de 2016 e sancionada pela Lei n. 13. 415, de 16 de fevereiro de 2017 (BRASIL, 2017). Como forma de discussão da reforma proposta pelo governo para o Ensino Médio brasileiro, destacamos a matéria "A nova cor do Ensino Médio" publicada pela revista Veja, em sua edição de 28 de setembro de 2016, com autoria de Cecília Ritto e Mônica

\footnotetext{
5 Ao discorrer sobre as reformas educacionais dos últimos anos, Dourado (2009) afirma que o princípio educativo neoliberal ganhou notoriedade nos projetos curriculares pós 1990, ocasionando uma crise de sentido para a escola pública brasileira. Desse ponto de vista, os projetos curriculares foram concebidos por meio de relaçóes de poder desfavoráveis, padronizando conteúdos e valores como se fossem universalmente legítimos, desconsiderando outros tidos como dispensáveis.

${ }^{6}$ Lembramos que o discurso da flexibilização já esteve presente na $1^{\text {a }}$ Lei de Diretrizes e Bases da Educação Nacional - Lei n. 4024/61 (BRASIL, 1961) e também na Lei de Reforma de $1^{\circ}$ e $2^{\circ}$ graus Lei n. 5692/71 (BRASIL, 1971) Na atual reforma do Ensino Médio, o discurso da flexibilização, da autonomia, da polivalência parece erigir como tábua de salvação para uma educação que caminha para o obsoleto.

${ }^{7}$ Não se trata de realizar uma análise exaustiva dos aspectos que envolvem o debate acadêmico sobre as políticas educacionais para o Ensino Médio, mas apenas discutir alguns pontos do tema com o intuito de contribuir com os estudos que estão sendo desenvolvidos.
} 
Weinberg. Naquela ocasião, as autoras da referida justificam a tese de que o modelo atual do Ensino Médio está falido, considerando a reforma do governo salvacionista.

$\mathrm{O}$ quadro $^{8}$ apresentado pelas autoras é espantoso, uma vez que nenhum questionamento é dirigido à proposta de reforma do governo, transparecendo apenas certo romantismo com os possíveis avanços proporcionados por tal reforma no ensino. Considerado ultrapassado, destacam Ritto e Weinberg (2016), o Ensino Médio brasileiro necessita de uma nova roupagem com o objetivo de formar indivíduos "mais" capacitados, "mais" produtivos, "mais" competitivos, deixando, portanto, de ser um ensino "menos" retrógrado. As autoras concordam que a escola não deve ter o propósito de fazer o aluno acumular conteúdos enciclopédicos, mas sim de desenvolver no indivíduo algumas competências e habilidades necessárias para a sua atuação no competitivo mercado de trabalho.

O crescente processo de globalização da sociedade capitalista e os mercados cada vez mais competitivos são apontados como elementos que indicam a prioridade de formação de trabalhadores em nível médio. É necessário, nessa perspectiva, que o Estado intensifique políticas educacionais voltadas para preparar os jovens e adultos estudantes para concorrer aos postos de trabalho disponíveis. Essa é a lógica que permeia o discurso dos documentos elaborados e editados pelos gestores do Banco Mundial e da UNESCO (SILVA, 2017, p. 187).

Este é o objetivo predominante das reformas neoliberais para o ensino: a formação de um novo perfil de trabalhador. $\mathrm{Na}$ atualidade, o mercado requer uma força de trabalho altamente qualificada, tecnicamente especializada e de indivíduos que tenham uma formação polivalente. Desse ponto de vista, qual a necessidade de uma formação sólida, reflexiva e abrangente em um contexto que requer uma preparação rápida e eficiente? As políticas neoliberais para a Educação nos dão a resposta.

O que é decisivo nessa discussão é o predomínio da lógica empresarial sobre a Educação, sempre atrelada ao capital internacional. Voltemos então à discussão sobre

\footnotetext{
${ }^{8}$ Não entraremos no mérito da discussão do perfil docente que vai atuar no Ensino Médio. Mas, um novo profissional surge nesse contexto: é o profissional com notório saber. Trata-se de um profissional sem formação em licenciatura, o que indica desconhecimento dos processos didático-pedagógicos da Escola Básica. Apenas as disciplinas das áreas técnicas e profissionalizantes contarão com a contribuição desse profissional especializado.
} 
as (contra) reformas educacionais. Outro item que merece a nossa atenção e que, possivelmente, provocará mudanças nas políticas de formação docente, refere-se às propostas de novas diretrizes e estratégias para a escola brasileira. Intencionando fomentar as discussóes neste ensaio, propomos uma reflexão sobre o novo Plano Nacional de Educação9 (PNE 2014 - 2024).

O PNE foi formulado a partir de um longo debate com a sociedade civil. Resultado de vários encontros propiciados pelas Conferências Nacionais de Educação - CONAES, o PNE envolveu os segmentos do campo educacional, aglutinando alunos, pais, gestores e outros profissionais dos diferentes sistemas de ensino. $\mathrm{O}$ projeto inicial recebeu muitas emendas, organizando no documento "diretrizes, objetivos, metas e estratégias de implementação para assegurar a manutenção e o desenvolvimento do ensino, em seus diversos níveis, etapas e modalidades, por meio de ações integradas das diferentes esferas federativas" (BRASIL, 2014, p. 8).

O processo de elaboração, discussão e de aprovação do PNE levantou muito otimismo acerca de suas propostas. Entretanto, gerou alguns limites na medida em que criou desafios que, se levados a sério, colocaria a educação brasileira em um nível elevado de qualidade. Segundo os estudiosos das políticas públicas educacionais, diversas metas, com prazos de concretização de um ou dois anos ainda não se efetivaram. Desse ponto de vista, "[...] o discurso neoliberal vem disseminando um conceito de qualidade equivocado, vista como algo consensual e unívoco, atrelado a um discurso hegemônico que veicula uma versão monossêmica (e mercadorizada) do termo [...]" (SANTANA, 2017, p. 85).

Esse raciocínio leva-nos a considerar que a noção de qualidade total em educação gera um enfraquecimento da autonomia docente, “[...] na qual uma educação de qualidade é aquela que faz os alunos tirarem boas notas nas avaliações externas, por isso estas são tão importantes" (SANTANA, 2017, p. 85). Decorre dessa situação que o objetivo dos sistemas de ensino passa a ser atingir metas

\footnotetext{
9 O Plano Nacional de Educação - PNE, com duração decenal, portanto 2014 - 2024, aprovado pela Lei n. 13.005, de 25 de junho de 2014 (BRASIL, 2014), está determinado pela Carta Magna de 1988 (artigo 214) e também pela Lei de Diretrizes e Bases da Educação Nacional - Lei n. 9394/96 (artigo 87) (BRASIL, 1996). O PNE (2014 - 2024) substituiu o PNE (2001 - 2010), instituído pela Lei n. 10. 172, de 9 de janeiro de 2001 (BRASIL, 2001). O atual PNE está organizado em 14 artigos, seguidos da descrição de 20 metas com suas respectivas estratégias para a Educação. A proposta para o Ensino Médio é apresentada mais especificamente na meta n. 3, caracterizada por 14 estratégias. Não é nosso objetivo central realizar um estudo minucioso dessas metas, mas apenas contribuir para a discussão das políticas educacionais para o Ensino Médio na atualidade.
} 
estipuladas pelos parâmetros internacionais de ensino, o que não significa um processo de aprendizado significativo, uma vez que é mais barato treinar estudantes para fazer provas (quando não os premiar) do que promover o pensamento crítico.

$\mathrm{O}$ argumento para associar a Educação ao mercado é apresentado por um discurso que defende a tese de que os níveis escolares estão abaixo da média porque a escola ainda está afastada da nova sociedade tecnológica que se apresenta na contemporaneidade. Das colocações acima, podemos afirmar a ideia de que a escola, amparada pelas políticas neoliberais, se apresenta de maneira superficial e homogeneizadora, fundada na eficiência por princípios quantitativos e pelo controle de um currículo único ${ }^{10}$ e uma avaliação igual para todos, cujo objetivo maior se torna atingir metas. Dentro dessa composição, a escola é reduzida meramente a alguns procedimentos técnicos, ainda que sofisticados, organizados por obsessóes métricas - a exemplo das metas e planos educacionais advindos da política neoliberal.

$\mathrm{Na}$ atual conjuntura marcada pelas políticas neoliberais para o campo educacional, a escola mais uma vez é convocada a rever a sua função de preparadora ${ }^{11}$ para a sociedade que se descortina neste novo século. Como decorrência dessa propositura, Bueno (2003, p. 83) esclarece que "a abordagem neoliberal sobre a educação abandona, portanto, os referenciais da cidadania e da emancipação do sujeito, substituindo-os pela liberdade do consumo educacional à disposição dos clientes".

A partir das consideraçóes levantadas anteriormente, Bueno (2003) propõe a necessidade de compreensão das estratégias conformistas e instrumentais do projeto econômico neoliberal reservadas para a Educação, fundamentando a crítica na

${ }^{10}$ Dentro do contexto das políticas neoliberais para a educação brasileira, o ministro da Educação Mendonça Filho, apresentou, em 6 de abril de 2017, a proposta da $3^{a}$ versão da Base Nacional Comum Curricular (BNCC), que objetiva nortear o currículo do Ensino Básico brasileiro. A BNCC apresenta os conteúdos para as áreas de linguagem, matemática, ciências humanas e da natureza na Educação Infantil, Fundamental e Médio. Segundo os estudiosos do campo curricular, Freitas (2012), Paro (1991) e Silva (1995), o currículo deve resultar de uma construção coletiva de cada escola. Logo, é importante a existência de diretrizes curriculares gerais. Entretanto, o currículo que deveria ser realmente desenvolvido poderia ser aquele construído em cada escola. Desse ponto de vista, a proposta da BNCC aponta para uma política de regulação baseada na avaliação segundo modelos privados de gestão. Lembrando que a BNCC toma como base o currículo norte-americano.

${ }^{11}$ Conforme o disposto no inciso $l 1$ do artigo 35: "a preparação básica para o trabalho e a cidadania do educando para continuar aprendendo, de modo a ser capaz de se adaptar com flexibilidade a novas condições de ocupação ou aperfeiçoamento posteriores” (BRASIL, 1996). 
144 | Ademir Henrique Manfré

manipulação da (semi) formação e no alinhamento da Educação à lógica de mercado. Nesse entendimento, são colocadas em discussão as estratégias neoliberais para a escola, ancoradas na perda de sua dimensão crítica por meio da conversão da Bildung (formação cultural) em Halbbildung (semiformação).

Para que se tenha uma ideia mais acertada desse pensamento, os filósofos frankfurtianos advertem para os limites dos sistemas e métodos da Educação, apontando para uma crise da formaçáo cultural que, de certo modo, provoca uma inércia em relação ao pensamento e capacidade de resistência aos mecanismos semiculturais. É essa questão que nos interessa e é nela que nos deteremos na segunda parte deste texto.

\section{O empobrecimento do pensar na educação: como resistir?}

"O homem de hoje não cultiva o que não pode ser abreviado"(VALÉRY, 1933, p. 112 apud BENJAMIN, 1989, p. 206).

Nesta parte do ensaio, temos como propósito geral refletir sobre o empobrecimento do pensar na escola. Procuramos expor os argumentos de Adorno relacionando-os com as teses defendidas por Walter Benjamin.

Vejamos como os frankfurtianos desenvolvem a crítica aos processos semiculturais e (de) formativos do pensar na Modernidade. Nosso objetivo principal é denunciar a fragilidade da formação cultural, apostando na ideia de que a experiência formativa, conforme apontada por Adorno (1996) ainda é um elemento de resistência aos processos semiformativos. 


\section{Teoria Critica, neoliberalismo e (semi) formação: há possibilidade de experiência (Erfahrung)?}

O tema da experiência ${ }^{12}$, ou melhor, de seu depauperamento, é um dos elementos presentes no pensamento adorniano. Os processos de tecnificação dos gestos e dos sentidos produzidos pelo ritmo da produção industrial, pelo avanço da técnica e pela complexificação da vida das grandes metrópoles no início do século passado, resultaram na estruturação de outra forma de percepção do mundo, de uma nova sensibilidade conformada aos desafios e ritmos cada vez mais velozes da vida urbana. Gestada em grande medida pelo desenvolvimento tecnológico, essa nova forma de perceber o mundo não corresponde mais à experiência (Erfahrung), mas, sim, ao seu depauperamento.

A instrumentalização da vida, sua danificação, será o tema central de Minima Moralia. Em relação a essa questão, Adorno (1996, p. 405) adverte sobre a tendência contemporânea em que há o predomínio das vivências ao invés de experiências. No lugar da experiência, o que se passa é uma experiência substitutiva que, como o próprio nome sugere, substitui precariamente aquela experiência “[...] por um estado informativo pontual, desconectado, intercambiável e efêmero, e que se sabe que ficará borrado no próximo instante por outras informações".

\footnotetext{
12 Experiência (Erfahrung) é um termo alemão e significa atravessar uma região durante uma viagem, por lugares desconhecidos. E a sua tradução para o latim - experi - tem como radical per, que significa "perímetro", ou seja, atravessar uma regiáo onde perigos podem nos assaltar. Com o advento da Modernidade, experiência significa prova, demonstração, tentativa, modelo. Essa concepção equivale ao processo de experimentação enquanto método científico que consiste em observar um fenômeno natural, utilizando-se de instrumentos, aparatos, tendo como modelo o cálculo matemático e o funcionamento mecanizado do relógio. Em Adorno e Benjamin, a experiência toma outros sentidos. A experiência é concebida por Benjamin (1989) como uma experiência aberta que se aproxima mais da alegoria por suscitar muitas leituras e inúmeros significados sobre ela. Graças a ela, o presente, o passado e o futuro poderão ser movimentados através da rememoração de tais experiências. Em "O narrador" fica explícito o dilema do homem moderno durante a passagem da experiência (Erfahrung) para a vivência (Erlebnis), que valoriza a vida particular e atomizada do indivíduo em detrimento da vida coletiva que existia até entáo. Ora, com o advento da Modernidade, essa experiência foi perdida. Nesse sentido, predomina a solidão em que o homem moderno se torna vítima da civilização urbana e industrial, não conhecendo mais a experiência (Erfahrung), que se baseia na memória de uma tradição cultural e histórica. Num mundo marcado pela barbárie das guerras mundiais, dos massacres em massa, da instrumentalização da vida, onde o minúsculo e frágil corpo humano se depara com toda a ostentação dos aparatos bélicos da guerra tecnológica, a experiência perde seu significado.
} 
No sentido da investigação proposta por Adorno, vários foram os temas escolhidos pelo autor para tratar do enfraquecimento e diluição do sujeito em meio a uma totalidade que o absorve e o aniquila. $\mathrm{O}$ processo de coisificação do homem mediado pela racionalidade instrumental e pela técnica que torna as pessoas semelhantes às máquinas é anotado por Adorno (2001) no aforismo "Devagar e sempre". O andar apressado das pessoas nas ruas, o culto à velocidade, o esporte exacerbado, a reificação do pensamento configura a produçáo da "nova subjetividade" na contemporaneidade. Em Adorno (2001, p. 165) "talvez no culto das velocidades possibilitadas pela técnica [...] se esconda o impulso de dominar o horror de correr, separando este do próprio corpo e excedendo-o de um modo soberano".

Esses elementos oferecem suporte às críticas apresentadas até o momento sobre os processos de tecnificação da vida. Aparece aqui a imagem do indivíduo ajustável, manipulável, transformado em mero objeto e sujeito à dominaçáo. Limitados em si mesmos, os comportamentos humanos não provocam nenhuma experiência, pois retira do pensamento a reflexão necessária para que algo seja compreendido em toda a sua complexidade.

À época de sua liquefação (utilizando um termo baumaniano), Adorno (2001) vê a forma assumida pelo indivíduo comparável a uma mônada. O filósofo atesta duas características essenciais da individualidade na sociedade reificada: primeira, a sua condição de célula apartada do contato ativo com o meio social; segunda, a dificuldade assumida pelo indivíduo de exercer uma crítica e um distanciamento sobre a realidade a qual está inserido.

Com o isolamento da mônada, a tensão entre indivíduo e sociedade tende, mediante a harmonização dos conflitos, a se desfazer e, com ela, a capacidade de resistência do indivíduo ao seu processo de depauperamento. $\mathrm{O}$ tema do empobrecimento da experiência aparecerá no aforismo "Longe dos tiros". Adorno (2001) constata uma inadequação do corpo humano às batalhas entre máquinas, tornando impossível a experiência propriamente dita. $O$ autor retoma alguns apontamentos feitos por Benjamin nos ensaios "O narrador" e "Experiência e pobreza" ao se referir à impossibilidade de narrar daqueles que retornaram da guerra por estarem amparados por uma vivência de choques. Refere-se também à estetização da guerra promovida pelos modernos meios de comunicação em que "a vida converteu-se numa sucessão intemporal de choques, entre os quais se abrem vazios, intervalos de paralisia” (ADORNO, 2001, p. 50-51).

No quadro das condiçôes da produção da consciência coisificada e da frieza generalizada, Adorno (2001) examina no aforismo "Apuros do particular" a perda da 
delicadeza dos vários hábitos civilizadores, tais como o andar vagaroso pela cidade, o fechar cuidadoso das portas, as viagens em trens outrora luxuosos, a conversáo do mobiliário da casa em ambientes puramente funcionais.

Vivendo em um contexto administrado pela racionalização, esse sujeito desaparece sem que houvesse outro para substituí-lo. Como vimos em outras passagens, o embrutecimento dos corpos está profundamente relacionado com o crescente processo de tecnificação do humano, o que, por sua vez, engendra uma pedagogia dos gestos e do corpo. O que está em destaque aqui é que a reflexão, se já náo desapareceu completamente, tende ao seu depauperamento, uma vez que os indivíduos, de qualquer forma, estão condenados a agirem segundo os interesses instrumentais da sociedade tecnocientífica.

Diante da amplitude que caracteriza a temática, Adorno (2001) se empenha em denunciar a deficiência da formação dos indivíduos. Vários temas foram escolhidos pelo autor como exemplos da dissolução do sujeito em meio a uma racionalidade instrumental que o absorve e o empobrece. $\mathrm{O}$ frankfurtiano enfatiza aspectos mais cotidianos da vida, mas que evidenciam certa decadência dos modos, da moral, da cultura e da educação, impossibilitando o indivíduo de exercer a reflexão e o pensamento crítico.

Adorno (1996) constata que a atual consciência não é apta à experiência. Por não possuir aptidão à experiência, essa consciência é caracterizada como coisificada. A perda da experiência, segundo o autor, é causada pela racionalidade do sempre igual. A consciência instrumentalizada poderia, por um lado, ser modificada pela experiência. Por outro, é precisamente ela que impede a efetivação da própria experiência. Disso resulta que a experiência desapareceu.

Ainda no debate sobre o depauperamento da experiência (Erfahrung), quando Benjamin (1994b) postula que a arte de narrar está em declínio, seu argumento se baseia na experiência cotidiana. Segundo ele, a velocidade da informaçáo, aliada a um capitalismo ascendente transformou por completo o que entáo tomávamos por tradição, abalando a experiência do homem. Opondo-se radicalmente à narração, a literatura de informação aspira a um consumo imediato, uma verificação imediata. Assim como no romance, a informação tem na imprensa a condição básica de sua ascensão.

No lugar da valorização de um saber proveniente de terras ou tempos longínquos, tal como valorizava os indivíduos da tradição, os indivíduos da Modernidade se reduzem a se apegar ao imediato, ao passageiro e sem vínculos com o 
outro que está próximo. Resta a esse indivíduo que surge da Modernidade a vivência (Erlebnis) (BENJAMIN, 1994b). É dessa mudança que surge a vivência do choque, vivência essa que empobrece a memória do homem. Essa pobreza é a pobreza das experiências comunicáveis e é uma das marcas do tempo infernal preconizado pela sociedade capitalista a que Benjamin se refere. Para o filósofo, o choque é parte integrante da vida moderna. Nesse contexto, a experiência não se submete a uma ordem contínua, mas passa a fazer parte de uma estrutura em que predominam inúmeras interrupçóes que constituem a vida cotidiana moderna.

Assim se chega ao tema da Educação. O depauperamento da escola fica evidente no saber fragmentado, no desprestígio do professor enquanto fonte de conhecimento, nas metodologias reificadoras, no pensamento rígido, nas propostas de reformas cujo objetivo último é qualificar para o mercado de trabalho em que o "aprender a aprender" é desvinculado do aprender a pensar, na formaçáo instrumental, no sistema de avaliação preocupado apenas em verificar se as metas foram alcançadas, desconsiderando todo o processo de aquisição do conhecimento. Conforme já expusemos no início dessa seção, nosso olhar sobre a Educação na contemporaneidade recai na tentativa de refletir sobre o processo de empobrecimento da cultura marcada por uma (semi) formação meramente técnica, descompromissada com o pensamento, com a autorreflexão, ancorada na política neoliberal que privilegia a competitividade, a produtividade, a eficiência e a meritocracia (desconsiderando a alteridade, pluralidade e a diferença).

Esta parte do trabalho foi uma tentativa de olhar para o texto de Adorno e Benjamin buscando refletir sobre o domínio da razão instrumental escondida sobre a aparente unilateralidade do progresso e, portanto, impeditiva de um processo de autorreflexão crítica sobre a cultura. Em Adorno (1996), a experiência se coloca em oposição ao pensar instrumental, que repete incessantemente o mesmo, incapaz de se relacionar com o diferente e limitada àquela apática adaptação. A consciência capaz de experiência permite outras possibilidades, consciente inclusive da diferença entre experimentar e náo experimentar. Adorno (1996), apesar da situaçáo fatalmente adversa, ainda indica que a experiência da própria perda da experiência seria uma tentativa de (re) construção da experiência.

Nosso intuito até aqui foi sublinhar que o enfraquecimento do pensar está ligado à semiformação, ao pensamento unidimensional, à ausência do pensamento autorreflexivo. Com isso, os diagnósticos levantados por Adorno foram tomados como possibilidades de tensão, de contradição e de resistência para refletirmos o modo como a Educação se organiza para atender aos reclames do capital. 


\section{Conclusão}

Ao analisar rapidamente o contexto histórico dos processos de transformações sociais provocadas pelas políticas neoliberais, constatamos que as novas configurações econômicas demarcam vários desafios para a escola. Em nosso entendimento, o primeiro deles se refere à política de formação/preparação do indivíduo para competitivo mercado de trabalho. Ao privilegiar apenas a instrumentalizaçáo do pensamento e o predomínio de conteúdos e metas a serem atingidas em determinado tempo e a baixo custo, as políticas neoliberais teriam se esquecido de levar em consideração os elementos não comunicáveis, não determináveis, não idênticos da prática educativa. $\mathrm{O}$ núcleo deste texto aponta para a crítica às políticas neoliberais que, ao privilegiar a meritocracia e a eficiência contribuem para o depauperamento da experiência na escola.

Chauí (1982) em "O que é ser educador hoje? Da arte à ciência: a morte do educador”, tratando do processo de instrumentalização do ensino e da formação, afirma que o mundo da técnica e da tecnologia impossibilita os indivíduos de realizarem experiências com a cultura para além dos modelos previamente estabelecidos pela performance da ciência e do mercado. Em Chauí (1982), explicitase um processo que privilegiou uma determinada concepção de Educação assentada na cientificização do processo didático-pedagógico, na organização burocráticoadministrativa das unidades de ensino e na centralização do processo decisório, oferecendo-se apenas o cumprimento dos objetivos da política neoliberal: qualificar rapidamente os alunos para atuar/executar funções, estas muitas vezes desvinculadas do aprender a pensar ${ }^{13}$.

Para compreendermos o modo como o ensino se transformou para atender as exigências do mercado de trabalho, discutimos, neste artigo, o modo como a cultura contemporânea se organizou em busca da eficiência e da eficácia, as quais passaram a ser perseguidas sem maiores consideraçóes enquanto à natureza do trabalho escolar, num processo em que valores eminentemente educacionais foram substituídos por outros de caráter econômicos: maximização da produção (formar mais em menos tempo) e minimização das despesas (menores gastos). Assim, o processo educativo

\footnotetext{
13 Adorno (1995), em "Educação - para quê?" apoia-se na argumentação de que a educação deve ultrapassar os aspectos adaptativos, visando a resistência e o inconformismo. Talvez os quatro pilares da educação definidos por Delors (2012) funcionem apenas mais como mecanismos adaptativos a uma sociedade que privilegia a polivalência do que a um processo de resistência aos instrumentos semiculturais.
} 
tornou-se um mero adaptar-se à realidade imediata e à esfera do consumo acoplada ao processo de produção.

O processo semiformativo, como dissemos, acarreta deficiências diversas. No campo educacional, a inaptidão dos indivíduos à experiência é uma das faces mais evidentes. Nesse sentido, nossa leitura foi guiada pelo pensamento adorniano objetivando refletir sobre a Educação que tem por finalidade a contradição e a resistência. Em Adorno (1996 e 2001) e Benjamin (1994a e 1994b), experiência é um conceito que não poderia se reportar ao sentido que usualmente lhe é atribuída pelas ciências empíricas, pois seu atributo pressupóe "propriamente um nível qualificado de reflexão" (ADORNO, 1996, p. 150).

De qualquer modo, mesmo considerando a escola como um espaço que constantemente "impede" a experiência, apontamos que, a partir das relaçóes estabelecidas entre formação (Bildung), memória, história, narração e fazer pedagógico, a experiência (Erfahrung) se torna um elemento de resistência e inconformismo para analisarmos as políticas neoliberais para o ensino.

Daí a importância de se resgatar, no processo educacional, a experiência formativa. Esse resgate significa a crítica radical aos momentos/situações que impeçam os indivíduos da capacidade de realizar experiências. Ir contra a semiformação é, para Adorno (1996), educar para a contradição e para a resistência. É, além disso, a luta para "mudar radicalmente as condiçôes sociais e materiais de produção que continuamente geram as múltiplas situaçôes de vivências que abafam as possibilidades de experiência" (PUCCI, 1997, p. 112).

- Ademir Henrique Manfré é Doutor em Educação, pela Universidade Estadual Paulista "Júlio de Mesquita Filho" (UNESP/SP). E Professor da Faculdade de Artes, Ciências, Letras e Educação da Universidade do Oeste Paulista (UNOESTE). E-mail: ademirmanfre@yahoo.com.br.

\section{Referências}

ADORNO, Theodor W. Teoria da semicultura. Educação e sociedade, Campinas, São Paulo, v. 17, n.

56, p. 388-411, set./dez. 1996. 
ADORNO, Theodor W. Educação... para quê? In: Theodor Adorno: educação e emancipação. Traduzido por Wolfgang Leo Maar. Rio de Janeiro: Paz e Terra, 1995, p. 139 - 154

ADORNO, Theodor W. Minima Moralia: reflexões a partir da vida danificada. São Paulo: Ediçóes 70 Ltda, 2001.

BENJAMIN, Walter. Experiência e pobreza. In: Obras escolhidas I. São Paulo: Brasiliense, 1994 a.

BENJAMIN, Walter. O narrador: consideraçóes sobre a obra de Nikolai Leskov. In: Obras escolhidas I. São Paulo: Brasiliense, 1994b.

BENJAMIN, Walter. Obras escolhidas II. São Paulo: Brasiliense, 1989.

BRASIL, Ministério da Educação. Lei n. 4.024/61, de 20 de dezembro de 1961. Lei de Diretrizes e Bases da Educação Nacional. Disponível em: http://www.planalto.gov.br/ccivil.leis.html. Acesso em 30 jun. 2017.

BRASIL, Ministério da Educação. Lei n. 5.692/71, de 11 de agosto de 1971. Fixa as Diretrizes e Bases para o ensino de $1^{\circ}$ e $2^{\circ}$ graus. Disponível em: http://www.planalto.gov.br/ccivil.leis.html. Acesso em 30 jun. 2017.

BRASIL. Ministério da Educação. Lei n. 9.394/96, de 20 de dezembro de 1996. Lei de Diretrizes e Bases da Educação Nacional. Disponível em: <http:/www.planalto.gov.br/ccivil.leis9394.html>. Acesso em: 30 jun. 2017.

BRASIL. Ministério da Educação. Lei n. 10.172, de 09 de janeiro de 2001. Plano Nacional da Educação (2001 - 2010). Série Legislação. Congresso Nacional. Brasília, DF. Disponível em: http://normaslegais.com.br/legislacao/leis.html. Acesso em: 30 jun. 2017

BRASIL. Ministério da Educação. Lei n. 13.005, de 25 de junho de 2014. Série Legislação. Plano Nacional da Educação (2014 - 2024). Congresso Nacional. Brasília, DF: 25 de junho de 2014.

BRASIL. Ministério da Educação. Lei 13.415, de 16 de fevereiro de 2017. Institui a política de fomento à implementaçâo de escolas de ensino médio em tempo integral. Disponível em: http://normaslegais.com.br/legislacao/lei13415-2017.htm. Acesso em: 30 jun. 2017

BUENO, Sinésio F. Pedagogia sem sujeito: qualidade total e neoliberalismo na educação. São Paulo: Annablume/FAPESP, 2003.

CHAUÍ, Marilena. O que é ser educador hoje? Da arte à ciência: a morte do educador. In: Brandão, Carlos (org.). O educador hoje. Rio de Janeiro: Graal, 1982, p. 51 - 70.

DELORS, Jacques. Educação: um tesouro a descobrir. Relatório para a UNESCO da Comissão Internacional sobre Educação para o século XXI. Brasília, DF: Ed. Cortez, MEC/UNESCO, 2012.

DOURADO, Luíz F. Políticas e gestão da educação no Brasil: novos marcos regulatórios. São Paulo: Xamã, 2009.

FREITAS, Luiz Carlos de. Os reformadores empresariais da educação: da desmoralização do magistério à destruição do sistema público de educação. Educação e Sociedade, Campinas, v. 33, n. 119, p. 379-404, abr./jun. 2012.

NEVES, Lúcia Maria Wanderley. A nova pedagogia da hegemonia: estratégias do capital para educar o consenso. São Paulo: Xamã, 2005.

OLIVEIRA, Dalila. Reformas educacionais na América Latina e os trabalhadores docentes. Belo Horizonte: Autêntica, 2003.

PARO, Vitor. Administração escolar: introdução crítica. São Paulo: Cortez, 1991.

PIMENTA, Selma G.; ANASTASIOU, Léa. Docência no ensino superior. São Paulo: Cortez, 2002. 
PUCCI, Bruno. A teoria da semicultura e suas contribuiçóes para a teoria crítica da educação. In: ZUIN, Antônio A. S.; PUCCI, Bruno; RAMOS-DE-OLIVEIRA, Newton (Orgs.). A educação danificada: contribuiçóes à Teoria Crítica da Educaçáo. Petrópolis, Rio de Janeiro: Vozes, 1997, p. 89-116.

RITTO, Cecília; WEINBERG, Mônica. A nova cor do ensino médio. Revista Veja: Ed. Abril, ed. 2497, ano 49, n. 39, 28 de set. 2016.

SANTANA, Andréia da C. O plano nacional da educação: mais do mesmo. In: MILITÃO, Andréia; PERBONI, Fábio (Orgs.). Plano Nacional de Educação: diversos olhares. Curitiba: CRV, 2017, p. 79-94.

SILVA, Iara A. As políticas de educação para o ensino médio no Brasil nas últimas décadas do século XX e início do século XXI: o que dizem os documentos e os pesquisadores. MILITÃO, Andréia; PERBONI, Fábio (Orgs.). Plano Nacional de Educação: diversos olhares. Curitiba: CRV, 2017, p. 186-205.

SILVA, Tomaz T. Alienígenas na sala de aula: uma introdução aos estudos culturais em educação. Petrópolis: Vozes, 1995.

Texto recebido em 10 de julho de 2017. Aprovado em 21 de julho de 2017. 